\title{
Genetic and phenotypic diversity in selected genotypes of tef [Eragrostis tef (Zucc.) Trotter
}

\author{
Sonia Plaza-Wüthrich, Gina Cannarozzi and ZerihunTadele* \\ University of Bern, Institute of Plant Sciences, Altenbergrain 21, 3013 Bern, Switzerland.
}

Accepted 26 March, 2013

\begin{abstract}
Tef [Eragrostis tef (Zucc.) Trotter] is an important staple food crop, especially in Ethiopia where it is annually grown on $\mathbf{2 . 8}$ million hectares of land. It is important for food security in the region, in spite of having a low yield, mainly due to lodging. In this study, 15 representative landraces as well as three improved varieties have been selected for in-depth characterization of many parameters, especially those implicated in yield. The genotypes were clustered into six groups, mainly based on agronomic traits and about $80 \%$ of the diversity in the genotypes could be explained on the basis of four principal components. In general, all traits investigated showed substantial diversity among genotypes, offering high chances for improving tef through direct selection or intra-specific hybridization. Moreover, in view of climatic changes, breeding with early maturing landraces such as Red dabi or Karadebi would be advantageous to cope with moisture scarcity during the later stage of crop maturity.
\end{abstract}

Key words: Eragrostis tef, landraces, improved varieties, genetic diversity, principal component analysis.

\section{INTRODUCTION}

Tef [Eragrostis tef (Zucc.) Trotter] is the main food crop of Ethiopia with an annual cultivation of 2.8 million hectares of land and a total production of 3.5 million tons (CSA, 2011). It grows in a wide range of environmental conditions and is more tolerant to drought, water logging and disease than other crops (Ketema, 1997). Tef is also considered to be a healthy food since its grain is free of gluten (Spaenij-Dekking et al., 2005), making it suitable for people suffering from celiac disease. Inspite of its advantages, the productivity of tef is very low mainly due to drought, biotic stress and lodging; the permanent displacement of the stem from the vertical position (Assefa et al., 2011). To aid selection of cultivars for breeding programs, the genetic diversity in natural and improved tef accessions is here characterized for many of these traits. Both the origin and diversity of tef is centered in Ethiopia and its domestication is estimated to have occurred between 4000 and 500 BC (Vavilov, 1951). Early studies of diversity include that of Mengesha who discovered a large variability in the majority of the characters investigated on the more than 100 panicle sample collections from unspecified areas of Ethiopia (Mengesha et al., 1965). Later, Ebba characterized 35 distinct tef ecotypes and classified them based on phenology and plant morphology (Ebba, 1975). Subsequently, several others have shown wide phenotypic diversity in the native (or landrace) tef germplasm (Adnew et al., 2005; Assefa et al., 2003, 2001; Chanyalew et al., 2009; Ketema, 1993; Tefera et al., 2003). The study of diversity is important for tef research programs whose main goals include the development of genotypes with high grain yield, tolerance or resistance to low moisture, improved lodging resistance, and desirable grain quality (Assefa et al., 2011). Currently these research 
programs have released 32 improved tef varieties to the farming community in Ethiopia mainly based on their yield performance (Kebebew Assefa, personal communication, 2012). For studies of tef genetic diversity, there are two major sources of tef germplasm. A collection of tef germplasm composed of 4395 accessions, is conserved at the Institute of Biodiversity Conservation (IBC) in Ethiopia (Demissie, 2001). In addition to this collection, the National Plant Germplam System (NPGS) of the United States Department of Agriculture possesses around 350 tef accessions collected from Ethiopia (http://www.ars-grin.gov/npgs/acc/acc_queries.html, 2005).

As in any crop improvement program, tef breeding relies mainly upon the germplasm resources existing in the genetic stock. Here, we studied diversity among18 tef genotypes including 15 of the 35 distinct tef ecotypes characterized by Ebba (1975). The 15 landraces have been selected based on the morphological characterization of Ebba in order to cover the variability observed (Ebba, 1975). While Ebba classified the ecotypes using morphological traits, here we consider additional traits including many agronomically important ones such as those implicated in yield. In addition, we expand the analysis to include cluster analysis, principle component analysis and correlation between the different traits and then compare the results of the natural ecotypes to improved varieties. This experiment, executed under controlled conditions, also minimizes considerable environmental variability present in the field grown genotypes.

\section{MATERIALS AND METHODS}

Fifteen selected landraces and three improved varieties of tef were sown in the growth rooms of the Institute of Plant Sciences, University of Bern during the Spring 2012 using a completely randomized design, with five independent plants from each genotype. The 15 landraces were $A d a$ (NPGS accession number: 524433), Addisie (524434), Alba (524435), Balami (524436), Beten (524437), Dabbi (524438), Enatite (524439), Gea Lamie (524440), Gommadie (524441), Karadebi (524442), Manyi (524443), Red dabi (524457), Rosea (524444), Tullu Nasy (524445) and Variegata (524446) while the three improved varieties were Dukem (DZ-01974), Magna (DZ-01-196), and Tsedey (DZ-Cr-37).

Plants of each genotype were grown in a growth chamber under long day conditions $\left(16 \mathrm{~h}\right.$ light at $22^{\circ} \mathrm{C}$, and $8 \mathrm{~h}$ dark at $18^{\circ} \mathrm{C}$; both with $65 \% \mathrm{RH}$ ). Five representative seedlings of each genotype were maintained for characterization. Three weeks after germination, the seedlings were transferred to a growth room with short day conditions $\left(8 \mathrm{~h}\right.$ light at $22^{\circ} \mathrm{C}$ and $16 \mathrm{~h}$ dark at $18^{\circ} \mathrm{C}$; both with $65 \% \mathrm{RH}$ ). The soil consisted of five parts topsoil, four parts turf and two parts of quartz sand and was autoclaved before use. Plants were fertilized once a week with HauertPlantaktiv 16+6+26 type K (Hauert HBG DüngerSchweiz, Grossaffoltern, $\mathrm{CH}$ ). The fertilizer contained $16 \%$ nitrogen, $6 \%$ phosphate, $26 \%$ potassium, $2 \%$ magnesium and micronutrients $(0.02 \%$ borate, $0.04 \%$ copper, $0.1 \%$ iron, $0.05 \%$ manganese, $0.01 \%$ molybdenum and $0.01 \%$ zinc).

Days to heading, days to maturity, and grain filling period were defined as the number of days from sowing until the first flower appeared; the number of days for all the grains of a panicle to mature and the period between these two time points, respectively. The number of tillers (culms except for the main culm), of panicles, of internodes, and of spikelets per panicle, as well as the culm and panicle lengths were determined at harvesting time. Plant height was divided into culm and panicle length. In addition, the length and diameter of the second culm internode starting from the base of the plant were measured. After harvesting, the main culm and the remaining tillers were separated and dried for $24 \mathrm{~h}$ at $60^{\circ} \mathrm{C}$ in order to determine the weight of the main culm as well as the total shoot biomass. Grains from the main culm and from the remaining tillers were weighed separately after threshing. Moreover, the weight of 100 grains from the main culm was also determined. Grain yield was defined as the grain weight per plant while shoot biomass refers to the sum of the culm and panicle weight. Harvest index was calculated as the ratio of the grain yield to the shoot biomass.

Statistical analysis was performed using SPSS Statistical 17.0 (IBM, Chicago, IL). Non-parametric tests were chosen as is appropriate for the number of replicates used and the nonhomogeneity of the variance in order to compare differences between the treatments $(p \leq 0.05)$. For $K$ independent samples, Kruskal-Wallis tests were used, whereas for two independent samples, Mann-Whitney $U$ tests were employed. For correlation analysis, the landraces and improved varieties were separated to highlight the difference in diversity between the native and the improved varieties. The Pearson correlation test was used on the mean values of traits including days to maturity, number of tillers, number of panicles, number of internodes per culm, second culm internode length, second culm internode diameter, plant height, shoot biomass per plant, grain yield per plant, weight of hundred grains, and harvest index. Cluster analysis (CA) and principal component analysis (PCA) were based on the above traits as well as grain color and panicle type. For the CA, the values for each variable were normalized to range between 0 and +1 and the clustering was made using the Hierarchical-Linkage between the groups and Squared Euclidean distance method using the $R$ package hclust version 2.14.1 with the average method (UPGMA) (R Development Core Team, 2005).

\section{RESULTS AND DISCUSSION}

\section{Morphological and phenotypic traits}

Several qualitative and quantitative traits were investigated in order to determine diversity among the selected tef genotypes (Table 1). Grain color (CG) and panicle branching type (PBT) were the two qualitative traits investigated. The color of tef grains can be grouped into three: white, pale white and brown. About $80 \%$ of all genotypes had white or pale white grains with only Dabbi, Gea Lamie, Karadebi and Variegata landraces having brown colored grain. While the grains of landraces possess all three types of colors, the grains of the three improved varieties had either white or pale white color since farmers prefer the white grain color which fetches higher prices than the brown-seeded grain. In this study, all three improved varieties had pale white or white grains while only a few brown-colored landraces were used.

Panicle branching type is also considered to be a valuable phenotypic trait as yield and other important traits might be associated with it. Similar to the grain color, all three improved tef varieties had only loose 
Table 1. Phenotypic traits investigated for 18 tef genotypes representing 15 landraces and three improved varieties.

\begin{tabular}{|c|c|c|c|c|c|c|c|c|c|c|}
\hline \multirow{2}{*}{$\begin{array}{l}\text { Genotype } \\
\text { Landrace }\end{array}$} & \multirow{2}{*}{ GC } & \multirow{2}{*}{ PBT } & \multirow{2}{*}{ NTP } & \multirow{2}{*}{ NPP } & \multirow{2}{*}{ NIC } & \multirow{2}{*}{ NPB } & $\mathrm{CL}$ & $\mathrm{PL}$ & SCIL & SCID \\
\hline & & & & & & & \multicolumn{2}{|c|}{$(\mathbf{c m})$} & \multicolumn{2}{|c|}{$(\mathrm{mm})$} \\
\hline Ada & Pale white & Loose & $1.0^{d}$ & $1.7^{d}$ & $3.6^{c d}$ & $27.2^{b c}$ & $34.7^{c d}$ & $32.1^{c}$ & $6.4^{e}$ & $1.35^{b c}$ \\
\hline Addisie & White & Compact & $2.0^{b c}$ & $2.8^{a b c}$ & $4.6^{b c}$ & $54.5^{a}$ & $30.6^{d}$ & $29.2^{d}$ & $8.6^{c d e}$ & $1.59^{a b}$ \\
\hline Alba & White & Loose & $0^{e}$ & $1.3^{e}$ & $4.3^{b c d}$ & $30.8^{b c}$ & $37.2^{c d}$ & $33.7^{c}$ & $11.2^{a b}$ & $1.84^{a}$ \\
\hline Balami & White & Loose & $0^{e}$ & $1.0^{e}$ & $6.0^{a}$ & $28.8^{b}$ & $43.6^{b}$ & $45.1^{a}$ & $9.9^{b c}$ & $1.29^{c}$ \\
\hline Beten & Pale white & Loose & $1.5^{b c d}$ & $2.0^{c}$ & $4.5^{b c}$ & $23.3^{c d}$ & $39.5^{c}$ & $35.7^{c}$ & $9.2^{c d}$ & $1.4^{b c}$ \\
\hline Dabbi & Brown & Very loose & $2.0^{b c}$ & $4.0^{a}$ & $4.0^{c}$ & $22.0^{d}$ & $40.5^{b c}$ & $25.3^{d}$ & $13.2^{a}$ & $0.89^{d}$ \\
\hline Enatite $^{*}$ & White & Loose & $1.2^{\text {bcde }}$ & $2.3^{b c}$ & $5.2^{a b c}$ & $22.8^{c d}$ & $34.2^{c d}$ & $35.4^{c}$ & $8.0^{d e}$ & $1.35^{b c}$ \\
\hline GeaLamie & Brown & Very loose & $2.0^{b c}$ & $3.7^{a b}$ & $3.0^{d}$ & $23.6^{c d}$ & $35.9^{c d}$ & $21.3^{d}$ & $6.4^{e}$ & $0.75^{d}$ \\
\hline Gommadie & Pale white & Compact & $1.0^{c d}$ & $1.5^{e}$ & $4.5^{b c}$ & $58.6^{a}$ & $36.8^{c d}$ & $26.3^{d}$ & $8.6^{c d e}$ & $1.47^{b c}$ \\
\hline Karadebi & Brown & Loose & $1.2^{c d}$ & $2.0^{b c}$ & $4.0^{c d}$ & $24.7^{c d}$ & $46.7^{a}$ & $29.4^{c}$ & $11.2^{a b}$ & $1.23^{c}$ \\
\hline Manyi & White & Loose & $1.0^{d}$ & $1.8^{d}$ & $5.6^{a b}$ & $26.2^{b c d}$ & $40.6^{b c}$ & $39.8^{b}$ & $9.9^{b c}$ & $1.43^{b c}$ \\
\hline Red dabi & Pale white & Very loose & $1.6^{b c d}$ & $3.3^{a b c}$ & $4.0^{c}$ & $23.6^{c d}$ & $32.0^{c d}$ & $27.4^{d}$ & $9.2^{c d}$ & $1.05^{c}$ \\
\hline Rosea & White & Loose & $0.2^{e}$ & $2.3^{b c}$ & $4.5^{b c}$ & $25.4^{b c d}$ & $34.1^{c d}$ & $34.1^{c}$ & $13.2^{a}$ & $1.55^{a b}$ \\
\hline TulluNasy & Pale white & Veryloose & $0.4^{d e}$ & $1.7^{d}$ & $3.7^{c d}$ & $21.8^{d}$ & $30.0^{d e}$ & $29.7^{c}$ & $6.4^{e}$ & $1.17^{c}$ \\
\hline Variegata & Brown & Loose & $0^{e}$ & $1.5^{e}$ & $3.7^{c d}$ & $30.5^{b}$ & $29.1^{d e}$ & $22.8^{d}$ & $8.6^{\text {cde }}$ & $1.53^{b}$ \\
\hline \multicolumn{11}{|l|}{ Improved } \\
\hline Dukem & Pale white & Loose & $3.0^{a b}$ & $2.0^{c}$ & $4.0^{c}$ & $30.0^{b}$ & $33.0^{c d}$ & $37.8^{b}$ & $9.3^{b c}$ & $1.68^{a b}$ \\
\hline Magna & White & Loose & $3.4^{a}$ & $3.8^{a b}$ & $4.6^{b c}$ & $27.4^{b c}$ & $36.6^{c d}$ & $32.9^{c}$ & $8.4^{c d e}$ & $1.41^{b c}$ \\
\hline Tsedey & White & Loose & $2.0^{b c}$ & $2.8^{b c}$ & $4.4^{b c}$ & $22.4^{d}$ & $29.6^{e}$ & $32.9^{c}$ & $7.5^{d e}$ & $1.25^{c}$ \\
\hline
\end{tabular}

Traits studied were: Grain color (GC), panicle branching type (PBT), number of tillers per plant (NTP), number of panicles per plant (NPP), number of internodes per culm (NIC), number of panicle branches (NPB), culm length (CL), panicle length (PL), second culm internode length (SCIL) and second culm internode diameter (SCID). Values followed by the same letter are not significantly different $(P<0.05)$.

anicles while the landraces had panicles ranging from very loose to compact. Among the18 genotypes investigated, only Addisie and Gommadie possessed compact panicles, while Dabbi, GeaLamie, Red Dabi and TulluNasy had very loose panicles. Tef breeders focus mostly on the branching types which give high yield. In tef, it has been shown that very loose, fairly loose and semi-compact panicle forms have higher yields than cultivars with very compact forms (Tefera et al., 1990). However, in our study under controlled conditions, no such correlation between the panicle branching type and the grain yield was observed (Table 1 (panicle branching type) and Table 2 (grain yield per plant)).

For the quantitatively determined traits, some significant differences $(p \leq 0.05)$ were obtained among the germplasms. Number of tillers per plant (NTP) refers to the number of branches that emerge at the base of the main stem excluding the main shoot. Although the majority of the genotypes had over one tiller per plant, landraces such as Alba, Balami and Variegata did not produce any tillers (Table 1 ). It is noteworthy that all improved varieties had at least two tillers. In general, landraces had a lower number of tillers compared to improved varieties.

The number of panicles per plant (NPP) is in general positively correlated to the number of tillers per plant as most tillers also develop panicles. Hence, as with the number of tillers, improved varieties had more panicles than the landraces (Table 1). However, in some genotypes the numbers of panicles were more than the numbers of tillers due to the fact that in some tillers more than one panicle could be found.

Numbers of panicle branches (NPB) refer to the amount of spikelets for the main panicle. This trait also contributed to a significant difference in investigated genotypes (Table 1). Addisie and Gommadie with over 50 spikelets per panicle had an exceptionally high number of spikelets. It is noteworthy that these two genotypes have the compact type of panicle and present smaller spikelets compared to the others panicle types (data not shown). Most genotypes including the improved varieties had less than half of the number of spikelets of these two landraces. Plant height is an important trait to be considered when developing lodging tolerant crops. It is the sum of culm length (CL) and panicle length (PL). Substantial differences were obtained for both traits among the genotypes tested (Table 1). The size of these two traits was in most cases proportional to each other except for Karadebi in which the tallest culm length is associated with one of the shortest panicles. The smallest genotypes such as Tsedey, and Variegata had a culm length below $30 \mathrm{~cm}$ whereas the tallest ones including Balami, and Karadebi attained more than 40 $\mathrm{cm}$. The three improved varieties had an intermediate 
Table 2. Yield and yield related traits investigated for the 18 tef genotypes representing 15 landraces and three improved varieties.

\begin{tabular}{|c|c|c|c|c|c|c|c|c|c|c|}
\hline Genotype & DH & DM & GFP & WMC & WAC & WMP & WAP & GY/PL & HGW & $\mathrm{HI}$ \\
\hline Landraces & & Days & & \multicolumn{6}{|c|}{$\mathrm{mg}$} & $\%$ \\
\hline Ada & $90.0^{a}$ & $110.0^{c}$ & $20.0^{e}$ & $205.0^{c}$ & $292.4^{d e}$ & $159.8^{c d}$ & $159.8^{a b}$ & $113.7^{a b}$ & $26.0^{b c d}$ & $28.9^{a}$ \\
\hline Addisie & $65.5^{f}$ & $90.0^{e f}$ & $24.5^{d}$ & $236.8^{C}$ & $497.8^{c d}$ & $169.5^{c d}$ & $234.7^{a b}$ & $168.8^{a}$ & $23.8^{d}$ & $20.6^{a}$ \\
\hline Alba & $78.0^{c d}$ & $105.0^{c d}$ & $27.0^{\text {cde }}$ & $317.3^{c}$ & $369.5^{d}$ & $186.0^{c}$ & $210.3^{a b}$ & $135.8^{a b}$ & $18.3^{f}$ & $23.8^{a}$ \\
\hline Balami & $86.2^{a}$ & $108.2^{c}$ & $22.0^{e}$ & $616.4^{a}$ & $636.5^{b c}$ & $395.9^{a}$ & $342.5^{a}$ & $229.9^{a}$ & $24.8^{b c d}$ & $23.6^{a}$ \\
\hline Beten & $87.5^{a}$ & $108.0^{c}$ & $20.5^{\mathrm{e}}$ & $402.3^{b}$ & $964.6^{a}$ & $225.9^{b}$ & $292.1^{a}$ & $131.0^{a}$ & $26.1^{b c}$ & $10.4^{b}$ \\
\hline Dabbi & $58.0^{g}$ & $87.4^{f g}$ & $29.4^{c d}$ & $188.6^{c}$ & $309.2^{d e}$ & $105.1^{e}$ & $180.9^{a b}$ & $38.5^{b c}$ & $30.3^{b}$ & $8.1^{1 c}$ \\
\hline Enatite* & $65.0^{f g}$ & $118.3^{a}$ & $53.3^{a}$ & $375.2^{b}$ & $499.6^{b c d}$ & $261.0^{b c}$ & $225.2^{a b}$ & $147.5^{\mathrm{a}}$ & $27.2^{\mathrm{bc}}$ & $20.1^{a b}$ \\
\hline GeaLamie & $58.0^{g}$ & $87.5^{f g}$ & $29.5^{c}$ & $100.5^{d}$ & $195.2^{e}$ & $68.0^{e}$ & $88.3^{b c}$ & $26.9^{c}$ & $19.6^{e f}$ & $8.7^{b c}$ \\
\hline Gommadie & $69.5^{e}$ & $92.5^{e}$ & $23.0^{e}$ & $424.8^{b}$ & $776.0^{a b}$ & $215.7^{b}$ & $338.8^{a}$ & $147.7^{a b}$ & $29.1^{b c}$ & $16.7^{a b}$ \\
\hline Karadebi & $60.2^{f}$ & $85.2^{g}$ & $25.0^{d}$ & $319.7^{c}$ & $550.7^{b c}$ & $102.6^{c}$ & $137.3^{a b}$ & $41.9^{b}$ & $22.2^{e f}$ & $6.6^{c d}$ \\
\hline Manyi & $86.8^{a}$ & $107.6^{c}$ & $20.8^{e}$ & $359.9^{a b}$ & $630.8^{b c}$ & $351.6^{b c}$ & $359.1^{a}$ & $290.1^{a}$ & $30.4^{b}$ & $31.6^{a}$ \\
\hline Red dabi & $56.5 h$ & $83.5^{g}$ & $27.0^{d}$ & $271.0^{c}$ & $450.6^{c d}$ & $166.6^{c}$ & $228.0^{a b}$ & $96.4^{b}$ & $24.8^{c d}$ & $16.9^{a b}$ \\
\hline Rosea & $70.3^{e}$ & $103.6^{c}$ & $33.3^{b c}$ & $328.8^{b}$ & $340.3^{d}$ & $194.7^{b c}$ & $203.5^{a b}$ & $95.4^{b c}$ & $32.6^{a}$ & $17.7^{a b}$ \\
\hline TulluNasy & $60.0^{f}$ & $88.8^{\text {ef }}$ & $28.8^{c d}$ & $143.7^{d}$ & $143.7^{e}$ & $80.7^{d}$ & $80.7^{c}$ & $43.1^{b c}$ & $21.9^{e f}$ & $18.5^{a b}$ \\
\hline Variegata & $72.4^{d e}$ & $90.4^{\mathrm{e}}$ & $18.0^{e}$ & $345.0^{c}$ & $345.0^{d}$ & $82.3^{d}$ & $82.3^{c}$ & $25.5^{c}$ & $22.4^{d e}$ & $5.4^{d}$ \\
\hline \multicolumn{11}{|l|}{ Improved } \\
\hline Dukem & $80.0^{b c}$ & $116.3^{b}$ & $36.3^{b}$ & $368.8^{b}$ & $660.0^{a b}$ & $192.0^{b c}$ & $253.6^{a}$ & $79.0^{b}$ & $24.8^{c d}$ & $8.0^{c}$ \\
\hline Magna & $83.4^{a b}$ & $122.8^{a}$ & $39.4^{b}$ & $292.0^{c}$ & $665.7^{a b}$ & $125.3^{c}$ & $182.7^{a b}$ & $33.3^{c}$ & $27.6^{b c}$ & $3.7^{d}$ \\
\hline Tsedey & $73.6^{d e}$ & $106.6^{d}$ & $33.0^{\circ}$ & $210.7^{c}$ & $317.9^{d e}$ & $82.8^{d}$ & $130.9^{a b}$ & $34.6^{b c}$ & $19.2^{f}$ & $7.6^{c}$ \\
\hline
\end{tabular}

${ }^{*}$ Enatite is a landrace and not the improved variety of the same name; Traits studied were: days to heading (DH), days to maturity (DM), grain filling period (GFP), weight of the main culm (WMC), weight of all culms (WAC), weight of the main panicle (WMP), weight of all panicles (WAP), grain yield per plant $(\mathrm{GY} / \mathrm{PL})$, hundred grains weight $(\mathrm{HGW})$ and harvest index $(\mathrm{HI})$. Values followed by the same letter are not significantly different $(\mathrm{P}<0.05)$.

culm and panicle-length.

Significant differences were also obtained among the tested genotypes for the number of culms per internode $(\mathrm{NCl})$ although no specific pattern was observed for this trait between the landraces and improved varieties (Table 1). Among the landraces Balami, Enatite, and Manyi had over five internodes while Gea Lamie had only three. Improved varieties had an intermediate number of internodes, varying between 4 and 4.6.

The other two morphological traits investigated were the length and diameter of the second culm internode from the base which has been shown to be important for tef lodging resistance (Hundera et al., 2000). Moreover, in rice, semi-dwarf mutants have been characterized by the shortening of a specific internode (Takeda, 1977; Yamamuro et al., 2000). Landraces such as Ada, Gea Lamie and Tullu Nasy had the shortest culm indicating the existence of diversity in this important trait known to be associated with lodging resistance. However, the diameter of this particular culm was the smallest for these genotypes which might have negatively affect the lodging resistance of the plant since experiments in other crops shows that lodging resistance is improved by increasing stem diameter (Kashiwagi et al., 2008).

Studies in other crops indicated that plants with short stature and internode length were more tolerant to lodging than taller ones (Peng et al., 2011). However, in the present study, no genotype with semi-dwarf stature and thick and short culm internode was found. The wide variability observed in each of these characters offers great perspectives for introgression of genotypes with thick and short basal culm internodes into semi-dwarf genotypes without sacrificing straw yield. Additional introgression of long panicles could be used to maintain the grain yield. For example, a lodging tolerant ideotype could be obtained by intra-specific hybridization between a semi-dwarf genotype with a long panicle (such as Dukem and Tsedey) and one with a wide second culm internode diameter (Alba).

\section{Yield and yield related traits}

Unlike Ebba (1975) we studied traits related to grain and straw yield of diverse tef genotypes including days to heading and maturity, shoot biomass, seed weight, grain yield, and harvest index. Days to heading (DH), days to maturity (DM), and grain filling period (GFP) varied significantly $(p \leq 0.05)$ across the different genotypes (Table 2). For days to heading, early flowering types were Dabbi and Gea Lamie with only 58 days from sowing to heading and the latest was Ada with up to 90 days. The improved varieties ranged from 74 days for Tsedey to 83 days for Magna. For days to maturity, early maturing types 
were Red dabi and Karadebi, with 84 and 85 days respectively, whereas the latest ones, the two improved varieties Dukem and Magna, needed up to 116 and 123 days, respectively. For the grain filling period, it ranged from 18 days for Variegata to up to 53 days for Enatite. The improved varieties showed intermediate values for both days to heading and maturity. Early heading genotypes were not always early maturing as shown with the landrace Enatite, which was an early heading genotype but a late maturating genotype, indicating a long grain filling period. The wide range in days to maturity (from 84 to 123 days) offers a huge flexibility for the selection of genotypes adapted to the diverse agroecological zones of Ethiopia, differing in the amount of precipitation received and the length of the growing season. Thus, fast maturating genotypes can be developed for areas with low rainfall to escape terminal drought. Moreover, these early maturing genotypes can also be employed in double cropping systems in high rainfall areas with long growing seasons.

The main culm was shown to contribute largely to the total culm and total panicle weights (at least $42 \%$ of the culm weight and at most $60 \%$ of the panicle weight) as well as to the grain yield (at least $45 \%$ ). The weight of main culm (WMC) and the weight of all culms per plant (WAC) were also substantially different among the genotypes tested. The weight of the main culm ranged from less than $200 \mathrm{mg}$ for Dabbi, Gea Lamie, and Tullu Nasy to more than $400 \mathrm{mg}$ for Beten and Gommadie, and even to $616 \mathrm{mg}$ for Balami. Regarding the total weight of all culms per plant, less than $200 \mathrm{mg}$ was observed for Gea Lamie and TulluNasy whereas the maximum weights were obtained for Beten and Gommadie with more than $750 \mathrm{mg}$. Improved varieties yielded high total culm weight except for Tsedey which had a total culm weight of only $318 \mathrm{mg}$. In general, there was positive correlation between WMC and WAC depending on the number of tillers per plant (Table 2). Exceptions to this were genotypes Beten, Gommadie and Manyi with giant tillers (data not shown).

The weight of main panicle (WMP) and weight of all panicles (WAP) were also significantly different among the tef genotypes. Genotypes such as Gea Lamie and Tullu Nasy with a small culm weight had also light panicle than the other landraces or improved varieties.

Grain yield per plant (GY/PL) was also significantly different among the genotypes. While the variability for this trait was small among the three improved varieties, large variability was observed among the landraces. However, the huge variability for this particular trait within the same genotype contributed for less observable differences among the genotypes. Compared to the landraces, improved varieties were low yielders. For instance, landraces such as Balami and Manyi gave over five-fold grain yield above the mean of the three improved varieties. This result is unexpected as improved varieties have been selected for higher yield. However, under the optimal water and fertilizer application conditions of the greenhouse, the landraces performed better than the improved varieties.

Although the improved varieties were selected in Ethiopia based on their superior grain yield, the landraces were not investigated along with the improved cultivars at high-input conditions in the field. When compared to the weight of all culms and panicles, we observed that improved varieties have intermediate to high weights indicating that the low grain yield might not be due to lower biomass (data not shown). The grain weight quantified here for 100 grains is influenced by the size and plumpness of the grain and is also an important trait since it has a direct contribution to the grain yield. Landraces such as Rosea and Dabbi had a significantly higher grain weight than the other genotypes. On the other hand, improved varieties had low to medium grain weight suggesting that both the total weight (grain yield) and the size are lower in the improved varieties.

Harvest index refers to the ratio of harvestable grain yield to the total above ground plant biomass. It is, therefore, an important parameter for breeders and agronomists in evaluating the performance of a germplasm under diverse climatic and soil conditions. Although most tested genotypes had a harvest index below 20\%, two genotypes namely Ada and Manyi scored over $28 \%$. Surprisingly, all improved varieties showed a harvest index of less than $10 \%$. These low values could be explained by the low grain yields obtained by the improved varieties with an intermediate shoot biomass. The harvest index values obtained for all genotypes varied from 3.7 to $31.6 \%$. This is in range with other studies of tef (Assefa et al., 1999, 2001; Ketema, 1993), whose data ranged between 5 and $39 \%$, but relatively low compared to other crops such as maize, rice and barley which have more than $50 \%$ (Lorenz et al., 2010; Peltonen-Sainio et al., 2008; Yang and Zhang, 2010). Surprisingly, the improved varieties of tef have very low harvest indexes. Because of the importance of tef straw as animal feed, improvement of the harvest index should not be at the sacrifice of high biomass but more focused on a higher grain yield.

\section{Correlation analysis}

Correlations of diverse traits were performed and significant correlations were found for all traits investigated except for second culm internode length (SCIL) (Table 3). Grain yield per plant (GY/PL) was correlated with all other remaining traits. These correlations were either positive or negative in the case of days to maturity (DM), number of tillers per plant (NTP) and number of panicles per plant (NPP). These latter three were positively correlated between themselves. Besides the previously mentioned correlations for the number of tillers, a positive influence was found with shoot 
Table 3. Pearson correlation coefficients among the following traits: days to maturity (DM), number of tillers per plant (NTP), number of panicles plant (NPP), number of internodes per culm (NIC), second culm internode length (SCIL), second culm internode diameter (SCID), plant height (PH), shoot biomass per plant (SB/PL), grain yield per plant $(\mathrm{GY} / \mathrm{PL})$, hundred grains weight (HGW), and harvest index $(\mathrm{HI})$.

\begin{tabular}{|c|c|c|c|c|c|c|c|c|c|c|}
\hline Trait & NTP & NPP & NIC & SCIL & SCID & $\mathbf{P H}$ & SB/PL & GY/PL & HGW & $\mathrm{HI}$ \\
\hline $\mathrm{DM}$ & $0.469^{* *}$ & $0.381^{* *}$ & 0.128 & -0.042 & -0.015 & -0.054 & 0.022 & $-0.376^{\star *}$ & 0.149 & -0.228 \\
\hline NTP & & $0.518^{* *}$ & -0.106 & -0.005 & -0.149 & -0.062 & $0.246^{\star}$ & $-0.316^{* *}$ & -0.104 & $-0.458^{* *}$ \\
\hline NPP & & & -0.127 & 0.127 & $-0.406^{\star *}$ & $-0.331^{\star *}$ & -0.020 & $-0.322^{\star *}$ & 0.054 & -0.192 \\
\hline $\mathrm{NIC}$ & & & & 0.039 & 0.210 & $0.507^{\star *}$ & $0.635^{\star \star}$ & $0.612^{\star *}$ & 0.211 & $0.417^{\star *}$ \\
\hline SCIL & & & & & -0.130 & 0.137 & 0.200 & -0.102 & 0.082 & -0.162 \\
\hline SCID & & & & & & 0.221 & $0.373^{\star *}$ & $0.261^{*}$ & -0.049 & 0.192 \\
\hline $\mathrm{PH}$ & & & & & & & $0.571^{* \star}$ & $0.539^{\star *}$ & $0.281^{*}$ & $0.401^{* *}$ \\
\hline SB/PL & & & & & & & & $0.519^{* *}$ & $0.247^{\star}$ & 0.236 \\
\hline GY/PL & & & & & & & & & $0.290^{*}$ & $0.809^{* *}$ \\
\hline HGW & & & & & & & & & & $0.313^{*}$ \\
\hline
\end{tabular}

* and ${ }^{* *}$ showed statistical significance at the 0.05 and 0.01 probability levels, respectively.

biomass per plant $(\mathrm{SB} / \mathrm{PL})$ and a negative one with harvest index $(\mathrm{HI})$. For the number of panicles per plant, positive correlations with second culm internode diameter (SCID) and plant height $(\mathrm{PH})$ were also observed. The number of internodes per culm (NIC) was positively correlated with plant height, shoot biomass per plant, grain yield per plant and harvest index. Concerning the second culm internode diameter, in addition to the negative correlation with the number of panicles per plant, two positive correlations were also found with shoot biomass and grain yield per plant. For plant height, additionally, positive correlations were observed with shoot biomass per plant, hundred grains weight and harvest index; these latter three positively correlated between them.

When correlations between landraces and improved varieties were compared in order to determine if breeding-induced selection has modified these correlations, a high level of divergence was observed, as no correlation existed in both types of genotypes (data not shown).

Correlation among the different traits is generally due to the presence of linkage and of the pleiotropic effects of different genes. Of course, environment also plays an important role in the development of these correlations (Ali et al., 2009). The number of significant Pearson correlation coefficients was 16 for landraces and only two for improved varieties; even these two correlations in the latter were not represented in the landraces (data not shown). In general, the correlations found in this study are in accordance with another study on tef landraces (Assefa et al., 2002). Surprisingly, however, we found that the second culm internode length is not correlated with any other trait. In contrast, grain yield per plant is influenced by all the remaining traits, suggesting that this trait is affected by many other traits. So far, no report has been found that shows negative correlations between the number of tillers and panicles and the grain yield as observed in the present study. This inverse relationship in tef between numbers of panicles and grain yield is not entirely unexpected as the majority of the grain yield was provided by the main panicle while all other panicles have little grain.

\section{Cluster analysis}

Cluster analysis using the same parameters as in the correlation analysis as well as grain color and panicle type resulted in the clustering of all 18 genotypes into six major groups comprising two to six genotypes (Figure 1). The biggest cluster, labeled 1, included landraces Alba, Rosea, Ada, Dabbi, Variegata, and the improved variety Tsedey, all having a low- to intermediate- shoot biomass per plant (that is, between 427 and 580 $\mathrm{mg}$ ). The second cluster contained four landraces, Addisie, Enatite, Karadebi and Red dabi, all characterized by intermediate shoot biomass of about $700 \mathrm{mg}$ per plant. All remaining groups 


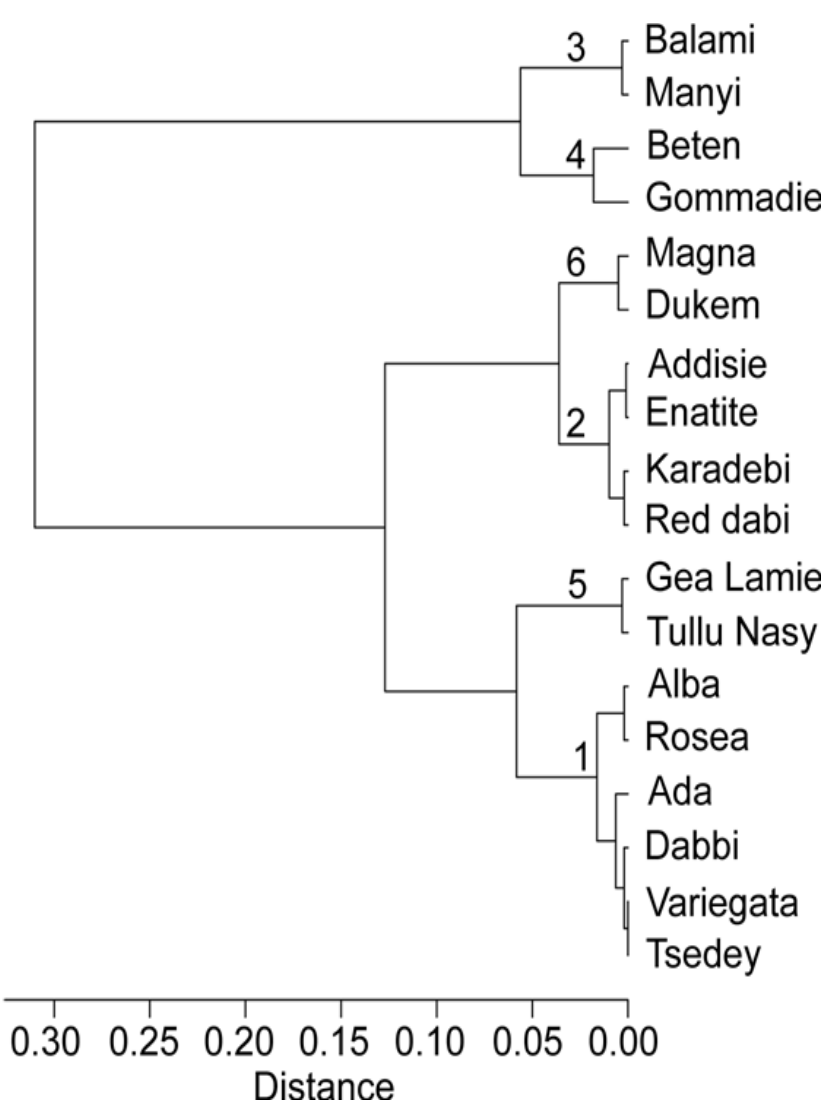

Figure 1. Dendrogram showing the pattern of clustering of 18 tef genotypes evaluated for 13 traits. The traits selected were grain color (GC), panicle branching type (PBT), days to maturity (DM), number of tillers per plant (NTP), number of panicles per plant (NPP), number of internodes per culm (NIC), second culm internode length (SCIL), second culm internode diameter (SCID), plant height (PH), shoot biomass per plant $(\mathrm{SB} / \mathrm{PL})$, grain yield per plant $(\mathrm{GY} / \mathrm{PL})$, hundred grain weight $(\mathrm{HGW})$ and harvest index $(\mathrm{HI})$.

were composed of only two genotypes and corresponded to extreme values of particular traits. Cluster 3 , containing Balami and Manyi, had the highest grain yield of more than $230 \mathrm{mg}$. The two extremes of the shoot biomass per plant made groups 4 and 5.Beten and Gommadie, with the highest shoot biomass of more than $1100 \mathrm{mg}$ were in Cluster 4 while Gea Lamie and Tullu Nasy were in Cluster 5 with the smallest biomass of less than $300 \mathrm{mg}$. Finally, the two improved varieties namely Dukem and Magna, characterized by more than three tillers per plant, were grouped in Cluster 6.

Our cluster analysis is in accordance with previous results showing that tef is a complex crop (Assefa et al., 1999). Except for cluster six which was grouped based on the number of tillers, the clustering of all other groups was based mainly on the shoot biomass and grain yield. No classification was based on other traits. The results indicated that the diversity presented in tef genotypes cannot be reduced into a few number of groups as was done in earlier studies (Mengesha et al., 1965).

\section{Principal components analysis}

Four principal components (PCs), having eigenvalues between 5.16 and 1.12, were observed (Table 4). Together, they explained about $80 \%$ of the total diversity among the studied tef genotypes.

Almost $40 \%$ of the total variation was explained by the first PC alone, and this was mainly due to variations in the grain color, days to maturity, the number of panicles and internodes per plant, the second culm internode diameter, plant height, the shoot biomass, the grain yield, and the harvest index. Similarly, $16 \%$ of the variance could be explained by the second PC, involving mainly the color of grain and the days to maturity, plus the type of panicle and the second culm internode length.

The third PC represented $15 \%$ and was mainly due to the number of tillers and of panicles and the weight of 100 grains whereas the other $9 \%$ of the variance explained by the fourth PC was mainly composed of the second culm internode diameter.

The broad phenotypic and agronomic diversity among the genotypes is also reflected in the principal component analysis which showed that the observed diversity could not be explained by only a few eigenvectors. In agreement with Assefa et al. (1999) who characterized 320 tef germplasm lines and explained $74 \%$ of the total variability using $4 \mathrm{PCs}$, we described $80 \%$ of the variability among 18 genotypes with an equal number of PCs. Moreover, both of these studies revealed that the major contributing traits were fairly well distributed among the phenotypic and agronomic characters studied.

The analysis of variance showed highly significant differences $(p<0.01)$ among the genotypes for all the traits investigated. Substantial variations have already been reported in various studies of the Ethiopian tefgermplasm (Adnew et al., 2005; Assefa et al., 2003, 2001; Chanyalew et al., 2009; Ketema 1993; Tefera et al., 2003).

The broad ranges found for all the traits investigated correspond to those observed in previous studies of tef germplasm. This suggests that for tef, studies done in a controlled environment with the advantage of more regulated conditions provided similar results to those conducted in field experiments.

In general, the current study is the first detailed comparison of tef landraces with improved varieties and focuses on selected traits involved in yield. The study was performed in a controlled environment and achieved similar results to previous studies conducted in the field.

Overall, this study has confirmed the broad spectrum of trait diversity in tef, which implies great opportunities for tef genetic improvement through either direct selection or intra-specific hybridization between parental lines with desirable traits. In addition, we show how mathematical characterization (such as correlation analysis) can be 
Table 4. Eigenvectors and eigenvalues of the first four principal components (PCs) for 18 tef genotypes.

\begin{tabular}{lcccc}
\hline \multirow{2}{*}{ Traits } & \multicolumn{4}{c}{ Eigenvectors } \\
\cline { 2 - 5 } & PC1 & PC2 & PC3 & PC4 \\
\hline GC & -0.723 & 0.554 & 0.002 & 0.014 \\
PBT & 0.396 & 0.762 & 0.207 & 0.062 \\
DM & 0.555 & -0.549 & 0.349 & 0.341 \\
NTP & -0.302 & -0.315 & 0.801 & 0.130 \\
NPP & -0.589 & -0.212 & 0.610 & -0.311 \\
NIC & 0.855 & -0.039 & 0.125 & -0.206 \\
SCIL & -0.213 & 0.782 & 0.186 & 0.187 \\
SCID & 0.624 & -0.006 & -0.140 & 0.663 \\
PLH & 0.790 & 0.131 & 0.193 & -0.036 \\
SB/PL & 0.685 & 0.250 & 0.517 & 0.182 \\
GY/PL & 0.882 & 0.085 & -0.070 & -0.296 \\
HGW & 0.404 & 0.197 & 0.513 & -0.386 \\
HI & 0.733 & -0.057 & -0.417 & -0.307 \\
Eigenvalue & & & & \\
Percent variation explained & 3.16 & 2.08 & 1.99 & 1.12 \\
Cumulative percent of & 39.72 & 15.97 & 15.34 & 8.59 \\
total variance explained & 39.72 & 55.69 & 71.03 & 79.62 \\
\hline
\end{tabular}

The traits chosen were: grain color (GC), panicle branching type (PBT), days to maturity (DM), number of tillers per plant (NTP), number of panicles per plant (NPP), number of internodes per culm (NIC), second culm internode length (SCIL), second culm internode diameter (SCID), plant height (PLH), shoot biomass per plant $(\mathrm{SB} / \mathrm{PL})$, grain yield per plant $(\mathrm{GY} / \mathrm{PL})$, hundred grain weight $(\mathrm{HGW})$ and harvest index $(\mathrm{HI})$. The weightings assigned to each variable, the eigenvalue, the percent of variation explained and the cumulative percent are indicated.

used to aid selection of candidates in breeding programs.

\section{ACKNOWLEDGEMENTS}

We are grateful to the Syngenta Foundation for Sustainable Agriculture and the University of Bern for financial support. A special thanks to Nicole Signer and Christopher Ball for the care of the plants. We are also grateful to United States National Plant Germplasm System (NPGS) for providing us with the different landraces.

\section{REFERENCES}

Adnew T, Ketema S, Tefera H, Sridhara H (2005). Genetic diversity in tef [Eragrostis tef (Zucc.) Trotter] germplasm. Genet. Resour. Crop. Ev0l. 52:891-902.

Ali MA, Nawab NN, Abbas A, Zulkiffal M, Sajjad M (2009). Evaluation of selection criteria in Cicer arietinum L. using correlation coefficients and path analysis. Aust. J. Crop Sci. 3:65-70.

Assefa K, Ketema S, Tefera H, Nguyen HT, Blum A, Ayele M, Bai G, Simane B, Kefyalew T (1999). Diversity among germplasm lines of the Ethiopian cereal tef [Eragrostis tef (Zucc.) Trotter]. Euphytica 106:87-97.

Assefa K, Merker A, Tefera H (2003). Multivariate analysis of diversity of tef (Eragrostis tef (Zucc.) Trotter) germplasm from western and southern Ethiopia. Hereditas 138:228-36.

Assefa K, Tefera H, Merker A (2002) Variation and inter-relationships of quantitative traits in tef (Eragrostis tef (Zucc.) Trotter) germplasm from western and southern Ethiopia. Hereditas 136:116-125.

Assefa K, Tefera H, Merker A, Kefyalew T, Hundera F (2001) Variability, heritability and genetic advance in pheno-morphic and agronomic traits of tef [Eragrostis tef (Zucc.) Trotter] germplasm from eight regions of Ethiopia. Hereditas 134:103-13.

Assefa K, Yu JK, Zeid M, Belay G, Tefera H, Sorrells ME (2011) Breeding tef [Eragrostis tef (Zucc.) trotter]: conventional and molecular approaches. Plant Breed. 130:1-9.

Chanyalew S, Tefera H, Singh H (2009). Genetic variability, heritability, and trait relationships in recombinant inbred lines of tef (Eragrostis tef (Zucc.) Trotter). Res. J. Agric. Biol. Sci. 5:474-479.

CSA (2011) Agricultural sample survey for 2010. CSA (Central Statistical Agency), Addis Ababa, Ethiopia. Statistical Bulletin 1.

Demissie A (2001). Tef genetic resources in Ethiopia., in: H. B. Tefera, G.; Sorrells, M. (Ed.), Narrowing the Rift. Tef Research and Development. Proceedings of the International Workshop on Tef Genetics and Improvement, Debre Zeit, Ethiopia, 16-19 October 2000.

Ebba T (1975) Tef cultivars. Part II Addis Ababa University, College of Agriculture, Dire Dawa, Ethiopia. http://www.arsgrin.gov/npgs/acc/acc_queries.html. (2005). USDA- ARS National Genetic Resources Program. Germplasm Resources Information Network (GRIN) database., National Germplasm Resources Laboratory, Beltsvill, MD.

Hundera F, Nelson LA, Baenziger PS, Bechere E, Tefera H (2000). Association of lodging and some morpho-agronomic traits in tef [Eragrostis tef (Zucc.) Trotter]. Trop. Agric. 77:169-173.

Kashiwagi T, Togawa E, Hirotsu N, Ishimaru K (2008). Improvement of lodging resistance with QTLs for stem diameter in rice (Oryza sativa

L.). Theor. Appl. Genet. 117:749-756.

Ketema S (1993). Tef (Eragrostis tef) breeding, genetic resources, agronomy, utilization and role in Ethiopian agriculture, Addis Ababa, Ethiopia. 
Ketema S (1997). Tef Institute of Plant Genetics and Crop Plant Research, Gatersleben / International Plant Genetic Resources Institute, Rome, Italy.

Lorenz AJ, Gustafson TJ, Coors JG, de Leon N (2010). Breeding Maize for a Bioeconomy: A Literature Survey Examining Harvest Index and Stover Yield and Their Relationship to Grain Yield. Crop Sci. 50:1-12.

Mengesha M, Pickett R, Davis R (1965). Genetic variability and interrelationships of characters in tef [Eragrostis tef (Zucc.) Trotter]. Crop. Sci. 5:155-157.

Peltonen-Sainio P, Muurinen S, Rajala A, Jauhiainen L (2008). Variation in harvest index of modern spring barley, oat and wheat cultivars adapted to northern growing conditions. J. Agric. Sci. 146:35-47.

Peng Z, Li X, Yang Z, Liao M (2011). A new reduced height gene found in the tetraploid semi-dwarf wheat landrace Aiganfanmai. Genet. Mol. Res. 10:2349-2357.

R Development Core Team (2005). R: A Language and Environment for Statistical Computing, R Foundation for Statistical Computing, Vienna, Austria.

Spaenij-Dekking L, Kooy-Winkelaar Y, Koning F (2005). The ethiopian cereal tef in celiac disease. New Eng. J. Med. 353:1748-1749.

Takeda K (1977). Internode elongation and dwarfism in some gramineous plants. Gamma Field Symp. 16:1-18.
Tefera H, Assefa K, Hundura F, Kefyalew T, Tefera T (2003). Heritability and genetic advance in recombinant inbred lines of tef [Eragrostis tef]. Euphytica. 13:91-96.

Tefera H, Ketema S, Tesemma T (1990). Variability, heritability and genetic advance in tef [Eragrostis tef (Zucc.) Trotter] cultivars. Trop Agric. 67:317-320.

Vavilov I (1951). The origin, variation, immunity and breeding of cultivated plants. Translated from the Russian by K. Starrchester Ronald Press, New York.

Yamamuro C, Ihara Y, Wu X, Noguchi T, Fujioka S, Takatsuto S, Ashikari M, Kitano H, Matsuoka M (2000). Loss of function of a rice brassinosteroid insensitive1 homolog prevents internode elongation and bending of the lamina joint. Plant Cell 12:1591-1605.

Yang JC, Zhang JH (2010) Crop management techniques to enhance harvest index in rice. J. Exp Bot. 61:3177-3189. 